\title{
PENATAAN KEBUN DAN PEMBUATAN KULINER DARI BUAH DAN REBUNG SALAK UNTUK MENDUKUNG PENGEMBANGAN DESA SIBETAN SEBAGAI DESA SENTRA AGROWISATA BERBASIS SALAK
}

\author{
I.N. Rai ${ }^{1}$, I.P. Sudana ${ }^{2}$, W. Wiraatmaja ${ }^{3}$, M. Sukewijaya ${ }^{4}$
}

\begin{abstract}
ABSTRAK
Pesatnya perkembangan pariwisata di Bali belum sinergis dengan sektor pertanian, bahkan berkembang polemik bahwa kamajuan pariwisata justru menyebabkan semakin terdesaknya sektor pertanian. Untuk menghindari semakin tidak seimbangnya perkembangan pariwisata dan pertanian, dikembangkanlah model pembangunan pertanian terintegrasi dengan pariwisata. Desa Sibetan yang terkenal sebagai sentra produksi salak, memiliki panorama alam yang indah, udara sejuk, dan lokaisnya dekat dengan berbagai destinasi wisata yang telah berkembang sehingga sangat potensial dikembangkan sebagai obyek agrowisata berbasis salak. Kegiatan pengabdian ini bertujuan menata kebun dan menyiapkan kuliner khas berbahan baku salak untuk mendukung pengembangan Desa Sibetan sebagai Desa Sentra Agrowisata berbasis salak. Kegiatan dilakukan selam 6 bulan dari Mei-Oktober 2017. Pelaksanaan menggunakan pendekatan masyarakat sasaran diajak berkerja bersama-sama (working with community) dan bekerja sambil belajar (learning by doing) melalui penerapan metode Entrepreneurship Capacity Building (ECB) dan Technology Transfer (TT), yaitu meningkatkan kualitas sumberdaya manusia/SDM anggota kelompok tani dan kelompok wanita tani melalui penyuluhan, pelatihan, pendampingan, transfer teknologi dalam menata kebun salak menjadi obyek agrowisata serta mengolah buah dan rebung salak menjadi kuliner. Melalui pengabdian ini telah berhasil ditata satu lokasi kebun milik kelompok tani sehingga di Desa Sibetan terdapat kebun salak yang tertata dengan baik dan siap dikunjungi wisatawan sebagai obyek agrowisata. Kelompok wanita tani mampu mengolah kulit buah salak menjadi teh salak, biji salak menjadi kopi salak, buah salak yang tidak laku terjual menjadi kurma salak, madu salak dan pia salak, serta rebung salak (pangkasan anakan salak) menjadi kare salak dan tumis salak.
\end{abstract}

Kata Kunci: agrowisata, kopi salak, rebung salak, Sibetan, IbDM

\begin{abstract}
The rapid development of tourism in Bali has not been synergistic with the agricultural sector, even the polemic develops that rapid growth of tourism actually causes the increasingly aggravated of agricultural sector. To avoid unbalanced development between tourism and agriculture it's developed model of agricultural integrated with tourism. Sibetan village which is famous as a center of salak production, has a beautiful natural scenery, fresh air, and its location close to various tourist destinations that have developed so that very potential to be developed as an agro-tourism destination. This community service aimed to manage of salak garden to be agro-tourism destination and preparation of specific culinary to support the development of Sibetan Village as the Agro-tourism Center based on salak. The activities were conducted during 6 months from May to October 2017. Implementation of activities used approach working with target communities and learning by doing through application of Entrepreneurship Capacity Building (ECB) and
\end{abstract}

\footnotetext{
${ }^{1}$ Staf Pengajar Prodi Agroekoteknologi, Fakultas Pertanian, Universitas Udayana; rainyoman@unud.ac.id

2 Staf Pengajar Prodi Industri Perjalanan Wisata, Fakultas Pariwisata, Universitas Udayana, Denpasar

${ }^{3}$ Staf Pengajar Prodi Agroekoteknologi, Fakultas Pertanian, Universitas Udayana

${ }^{4}$ Staf Pengajar Prodi Agroekoteknologi, Fakultas Pertanian, Universitas Udayana
} 
Technology Transfer (TT) method, which was to improve the quality of human resources of farmer group members and women's group organization members through counseling, training, mentoring, and technology transfer. Through this community service has been succeeded in arranging one location of farmer's salak garden as an agro-tourism destination and ready to be visited by tourists. Women's group organization members have succeeded in processing the skin of salak fruit into salak tea, salak seeds into salak coffee, flesh fruit into kurma salak, honey salak and pia salak, and "rebung salak" become salak curry and sauteed salak.

Keywords : agrotourism, coffee salak, salak shoot, Sibetan, IbDM.

\section{PENDAHULUAN}

Perkembangan pariwisata yang pesat di Bali belum sinergis dengan sektor pertanian, bahkan berkembang polemik bahwa kamajuan pariwisata justru menyebabkan semakin terdesaknya sektor pertanian. Saat ini sektor pariwisata memberikan kontribusi yang sangat signifikan bagi perekonomian Bali, tetapi perkembangan yang asimetris dengan dominasi sektor pariwisata telah berdampak pada termarginalisasinya partanian, padahal pertanian bukan saja sebagai pilar penting dalam mendukung keberhasilan pariwisata, tetapi juga sebagai sektor strategis yang harus tetap dijaga karena merupakan hajat hidup bagi sebagian besar masyarakat Bali.

Integrasi pertanian dengan pariwisata dalam bentuk agrowisata atau agro-ekowisata telah terbukti dapat meningkatkan ekonomi petani sehingga tumbuh persespi positif terhadap pariwisata dikalangan masyarakat pedesaan di Bali (Windia at al., 2011; Sumiyati et al., 2011). Oleh karena itu, pembangunan pertanian yang sinergis-komplementaris dengan pariwisata akan memberikan hubungan saling menguntungkan (simbisosis mutualistik) dan saling menguatkan antara pertanian dan pariwisata (Goodwin, 2008; Nurisjah, 2001; Budiarti et al., 2013), sehingga dalam jangka panjang pariwisata Bali diharapkan dapat berperan sebagai pendorong sektor pertanian untuk selalu meningkatkan kuantitas, kualitas dan kontinyuitas produk (Sudana dan Mahadewi, 2015), dan melestarikan lingkungan untuk mewujudkan green tourism dan sustainable tourism (Suyastri, 2012; Budiarti dan Listyanti, 2015).

Desa Sibetan yang berlokasi di Kecamatan Bebandem, Kabupaten Karangasem memiliki luas wilayah 1.125 ha, sebagian besar merupakan lahan kering/tegalan (912,62 ha) yang ditanami tanaman salak, sisanya dipergunakan sebagai lahan pekarangan, persawahan dan lahan lain. Dominasi penggunaan lahan untuk salak $(81,12 \%)$ meyebabkan lebih dari $80 \%$ mata pencaharian penduduk menggantungkan hidup dari komoditi salak sehingga sejak dulu Desa Sibetan terkenal sebagai sentra produksi salak di Bali. Dengan hamparan kebun menghijau pada bentang alam yang unik, desa ini memiliki panorama alam yang indah dengan view gunung (Gunung Agung) di Utara, view lembah di Timur dan view pantai di Selatan. Udaranya bersih, sejuk, dan menyegarkan sehingga sangat potensial dikembangkan sebagai tempat wisata, tempat trekking atau tempat peristirahatan bagi wisatawan mancanegara maupun domestik. Hal tersebut semakin diperkuat oleh lengkapnya berbagai sarana prasarana yang ada seperti listrik, telpon, internet, dan air PDAM.

Berdasarkan profil tahun 2014, Desa Sibetan memiliki penduduk sebanyak 8.725 jiwa (laki-laki 4.342 jiwa dan perempuan 4.383 jiwa) dengan jumlah kepala keluarga $2.186 \mathrm{KK}$. Ironisnya walaupun wilayahnya subur dengan ikon sebagai sentra penghasil salak, ternyata $344 \mathrm{KK}(15,74 \%)$ penduduknya tergolong rumah tangga miskin (pra sejahtera). Masih banyaknya penduduk pra sejahtera memerlukan partisipasi semua pihak untuk ikut berkontribusi dalam mengentaskannya.

Walaupun memiliki potensi agrowisata yang besar didukung oleh lokasi geografis yang strategis dan sangat mudah dapat dikaitkan dengan rute perjalanan wisata dari dan ke pusat-pusat pariwisata

\section{8 | BULETIN UDAYANA MENGABDI}


yang telah berkembang seperti Kuta, Sanur, Nusa Dua, Ubud, Goa Gajah, dan Pura Besakih, tetapi potensi tersebut belum digarap dengan baik sehingga perkembangan pariwisata yang pesat di Bali belum dirasakan manfaatnya oleh masyarakat Desa Sibetan. Hal tersebut disebabkan oleh lemahnya kemampuan sumber daya manusia (SDM) desa dalam mengelola potensi yang dimiliki dimana petani dan masyarakat belum mampu mengkemas berbagai potensi yang ada menjadi something to see (sasuatu yang dapat dilihat), something to do (sesuatu yang dapat dikerjakan), something to buy (sesuatu yang dapat dibeli), dan something to learnt (sesuatu yang dapat dipelajari) oleh wisatawan. Terkait dengan hal itu, pengabdian ini dilakukan dengan tujuan menata kebun dan menyiapkan kuliner khas berbahan baku salak untuk mendukung pengembangan Desa Sibetan sebagai Desa Sentra Agrowisata berbasis salak.

Kegiatan penataan kebun dibutuhkan karena salama ini belum ada satu lokasi kebun salak di Desa Sibetan yang tertata rapi yang siap dikunjungi oleh wisatwan. Berdasarkan hasil wawancara dengan Kepala Desa Sibetan, apabila ada grup wisatawan yang tertarik untuk mengunjugi perkebunan salak di Sibetan maka tour guide atau masyarakat desa akan kebingungan untuk menunjukkan lokasi yang siap dikunjungi. Sedangkan kegiatan pembuatan kuliner berbahan baku buah dan rebung salak diperlukan agar wisatawan yang nantinya berkunjung ke obyek agrowisata salak dapat menikmati kuliner khas dari salak. Disamping itu, kegiatan pembuatan kuliner dari buah salak dimaksudkan untuk mendorong berkembangnya penanganan pasca panen dan pengolahan hasil salak yang saat ini belum berkembang dengan baik sehingga saat produksi buah tinggi atau harga jual rendah banyak buah salak terbuang percuma. Tekanan semakin bertambah karena sistem pemasaran yang tidak efisien, sangat ditentukan oleh pengijon, pengepul dan pedagang/distributor buah yang menyebabkan banyak petani pada musim panen raya membiarkan buahnya tidak dipanen (busuk di pohon). Sedangkan pembuatan kuliner dari rebung salak dimaskudkan untuk memanfaatkan limbah yang dihasilkan dari pangkasan anakan yang tidak berguna, dengan mengambil rebungnya (bahasa Bali: empol) untuk dijadikan kuliner khas agrowisata salak Sibetan.

\section{METODE PELAKSANAAN}

Berdasarkan potensi yang ada di Desa Sibetan, dalam pengabdian ini dilakukan kegiatan penataan kebun dan pembuatan kuliner khas berbahan baku buah dan rebung salak (empol dari pangkasan anakan salak yang tidak berguna). Kegiatan berlangsung selama enam bulan dari Mei-Oktober 2017 dengan pendekatan masyarakat sasaran diajak berkerja bersama-sama (working with community) dan bekerja sambil belajar (learning by doing) melalui penerapan metode Entrepreneurship Capacity Building (ECB) dan Technology Transfer (TT). Metode ECB dan TT dilakukan untuk meningkatkan kemampuan dan kualitas SDM lokal dalam pengembangan agrowisata (Rai et al., 2016), dalam hal ini yaitu meningkatkan kualitas SDM petani salak dan wanita tani melalui penyuluhan, pendampingan, dan transfer teknologi dalam menata kebun salak menjadi obyek agrowisata serta mengolah buah dan rebung salak menjadi produk kuliner khas.

Kelompok sasaran dalam penataan kebun salak adalah anggota Kelompok Tani Kerta Semaya Desa Sibetan. Pelaksanan dilakukan dalam 2 tahap, yaitu tahap penyuluhan dan tahap pendampingan. Tahap penyuluhan dilakukan kepada 60 anggota kelompok tani untuk menjelaskan tentang potensi, tujuan, teknologi yang akan ditransfer, tata cara dalam menata kebun sebagai obyek agrowisata, dan langkah-langkah dalam menyiapkan paket something to see, something to do, something to buy, dan something to learnt bagi wisatwan yang akan berkunjung. Pada tahap pendampingan, tim pengabdian mendampingi dan bekerja bersama-sama dengan anggota kelompok tani dalam penataan kebun dengan menerapkan dan mentransfer teknologi cara budidaya yang baik dan benar (Good Agricultural Practices/GAP) mulai dari pembersihan kebun, penjarangan pohon,

VOLUME 17 NOMOR 2, APRIL 2018 | 59 
pemupukan, pemangkasan, pengaturan tanaman penaung, pemangkasan daun, pemangkasan bekas tandan bunga dan tandan buah, pemagaran kebun, serta cara panen dan pasca panen yang baik, dengan maksud agar kebun tertata rapi, pertumbuhan dan produksi pohon salak optimal dengan kuantitas, kualitas, dan kontinyuitas buah yang maksimal. Pendampingan dilakukan secara kontinyu melalui pertemuan secara berkala sampai kebun tertata rapi dan tersedia paket something to see, something to do, something to buy, dan something to learnt bagi wisatwan yang akan berkunjung ke kebun.

Kelompok sasaran dalam pembuatan kuliner berbahan baku buah salak dan rebung salak adalah Kelompok Wanita Tani "Agro Abian Salak" Desa Sibetan. Mirip seperti pelaksanaan penataan kebun salak sebagai obyek agrowisata, metode pelaksanaan dalam pembuatan kuliner juga terdiri atas 2 tahap, yaitu tahap penyuluhan dan pelatihan serta tahap pendampingan. Tahap penyuluhan dan pelatihan diikuti oleh 70 orang anggota KWT untuk menjelaskan tentang potensi, tujuan, teknologi yang akan ditransfer, tata cara membuat dan mengkemas kuliner berbahan baku buah dan rebung salak. Sedangkan tahap pendampingan dilakuan dengan cara tim pengabdian bekerja bersama-sama dan mendampingi anggota KWT dalam mempraktekkan cara membuat, mengkemas dan memberikan label (lebelling) produk kuliner yang dihasilkan. Pendampingan dilakukan secara kontinyu melalui pertemuan secara berkala sampai didapatkan resep yang terbaik, bentuk kemasan dan label yang paling menarik, serta tersedia something to buy dan something to do apa bila ada wisatawan yang berkunjung ingin ikut mempraktekkan bagaimana cara membuat kuliner berbahan baku buah dan rebung salak.

\section{HASIL DAN PEMBAHASAN}

\subsection{Penataan Kebun Salak sebagai Obyek Agrowisata}

Melalui kegiatan ini telah berhasil dilakukan penataan satu lokasi kebun salak milik kelompok tani menjadi kebun yang tertata rapi (Gambar 1) dan telah berhasil pula disiapkan paket something to see, something to do, something to buy, dan something to learnt bagi wisatwan yang akan berkunjung sehingga kebun salak hasil penataan siap dijadikan sebagai kebun agrowisata. Penataan kebun disertai dengan transfer teknologi GAP oleh tim pengabdian melalui pengadaan demplot, dengan harapan nantinya para petani salak mau dan mampu menata kebunnya sendiri sebagai kebun agrowisata. Adapun kegiatan yang dapat dijadikan sebagai atraksi pada kebun agrowisata salak di Desa Sibetan yaitu kondisi kebun yang tertata rapi dengan lingkungan yang asri dan sejuk (something to see), tahapan-tahapan budidaya salak dengan GAP (something to do), buah salak organik dengan rasa khas, enak, dan renyah (something to buy), serta kelestarian lingkungan pada perkebunan salak, keanekaragaman 13 jenis plasma nutfah salak Desa Sibetan, dan budaya masyarakat yang terkait dengan kebaradaan salak (something to learnt). 

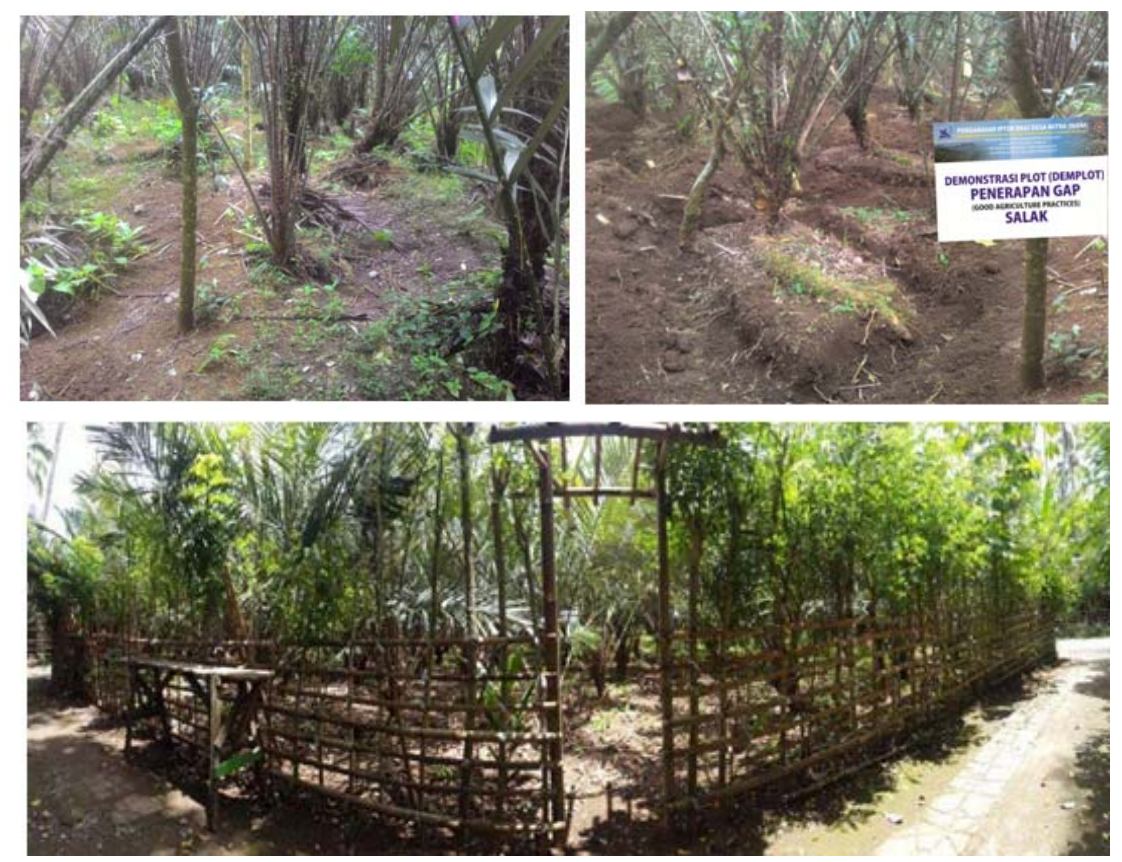

Gambar 1. Kondisi kebun salak sebelum ditata (kiri atas), saat penataan (kanan atas) dan kebun setelah ditata dibuatkan pagar keliling (bawah)

Keberhasilan kegiatan penataan kebun menjadi obyek agrowisata tidak hanya tercermin dari tertatanya satu lokasi kebun milik kelompok tani dan telah disiapkannya paket atraksi wisata, tetapi juga dari tingkat kepuasan dan peran serta aktif anggota kelompok tani dalam mengikuti penyuluhan dan bekerja bersama-sama dalam pendampingan. Penyuluhan berlangsung lancar dan diikuti dengan sangat antusias oleh peserta yang dibuktikan dengan adanya berbagai pertanyaan, tanggapan, dan keseriusan mereka dalam menyimak dan mempeerhatikan materi yang disuluhkan. Pada sesi pendampingan penataan kebun, petani sangat antusias dan terlibat secara aktif mempraktekkan teknologi yang ditransfer oleh tim pengabdian, melaksanakan kegiatan penerapan GAP, melakukan pembersihan kebun dan membuat pagar keliling, dan lain-lain sehingga kebunnya tampak lebih asri dan indah. Tabel 1 menunjukkan $68 \%$ peserta penyuluhan merasa sangat puas dengan pelaksanaan kegiatan penyuluhan sementara yang menjawab kurang puas dan tidak puas $0 \%$. Terhadap materi penyuluhan yang diberikan, $64 \%$ menyatakan sangat puas dan sisanya $36 \%$ merasa puas. Demikian pula tentang metode cara penyuluh/instruktur memberikan penyuluhan dan tingkat kepuasan secara keseluruhan terhadap pelaksanaan penyuluhan masing-masing $60 \%$ dan $68 \%$ responden menyatakan sangat puas dan sisanya masing-masing $40 \%$ dan 32\% menyatakan puas. Sedangkan Tabel 2 menunjukkan, setelah mendapatkan penyuluhan dan pendampingan $68 \%$ petani sangat mau menerapkan/mempraktekkan GAP dalam budidaya salak di kebunnya sendiri, sisanya 32\% menyatakan mau, sedangkan yang menjawab kurang mau dan sangat tidak masu masing-maisng $0 \%$. Jawaban yang agak pesemistis disampaikan oleh peserta pelatihan ketika ditanyakan apakah mau melakukan penataan kebun salak untuk obyek agrowisata di kebun sendiri, hanya $28 \%$ menyatakan sangat mau dan $72 \%$ menyatakan mau. Setelah didalami, yang menyatakan sangat mau adalah mereka yang kebunnya bisa dilalui kendaraan roda empat. Artinya, petani yang kebunnya tidak bisa dilalui roda empat tidak seantusias petani yang kebunnya dapat dilalui kendaraan roda empat.

VOLUME 17 NOMOR 2, APRIL 2018 | 61 
Tabel 1. Tingkat Kepuasan Peserta Pelatihan Penarapan GAP Dan Penataan Kebun Untuk Obyek Agrowisata

\begin{tabular}{|c|l|c|c|c|c|}
\hline \multirow{2}{*}{ No } & \multicolumn{1}{|c|}{ Pertanyaan } & \multicolumn{2}{c|}{ Tingkat Kepuasan Peserta Penyuluhan (\%) } \\
\cline { 3 - 6 } & \multicolumn{1}{|c|}{$\begin{array}{c}\text { Sangat } \\
\text { puas }\end{array}$} & Puas & $\begin{array}{c}\text { Kurang } \\
\text { Puas }\end{array}$ & $\begin{array}{c}\text { Sangat tidak } \\
\text { Puas }\end{array}$ \\
\hline 1 & $\begin{array}{l}\text { Bagaimana pendapat bapak/saudara } \\
\text { tentang pelaksanaan kegiatan penyuluhan } \\
\text { ini. }\end{array}$ & 68 & 32 & 0 & 0 \\
\hline 2 & $\begin{array}{l}\text { Bagaimana menurut bapak/saudara } \\
\text { mengenai materi penyuluhannya. }\end{array}$ & 64 & 36 & 0 & 0 \\
\hline 3 & $\begin{array}{l}\text { Bagaimana menurut bapak/saudara } \\
\text { mengenai metode atau cara } \\
\text { pelatih/instruktur dalam memberikan } \\
\text { penyuluhan. }\end{array}$ & 60 & 40 & 0 & 0 \\
\hline 4 & $\begin{array}{l}\text { Apakah bapak/saudara merasa puas } \\
\text { mengikuti penyuluhan ini. }\end{array}$ & 68 & 32 & 0 & 0 \\
\hline
\end{tabular}

Catatan: jumlah responden 25 orang.

Tabel 2. Tingkat Mau Tidaknya Peserta Penyuluhan Dan Pendampingan Untuk Mempraktekkan Hasilnya Di Kebun Sendiri

\begin{tabular}{|c|l|c|c|c|c|}
\hline \multirow{2}{*}{ No } & \multicolumn{1}{|c|}{ Pertanyaan } & \multicolumn{3}{|c|}{ Tingkat "kemauan" peserta mempraktekkan di kebunnya } \\
\cline { 3 - 6 } & \multicolumn{1}{|c|}{ sendiri (\%) } \\
\cline { 3 - 6 } & Sangat mau & Mau & $\begin{array}{c}\text { Kurang } \\
\text { Mau }\end{array}$ & Sangat Tidak Mau \\
\hline 1. & $\begin{array}{l}\text { Apakah bapak/saudara mau } \\
\text { menerapkan/memprakraktekkan } \\
\text { GAP dalam budidaya salak di } \\
\text { kebun sendiri. }\end{array}$ & 68 & 32 & 0 & 0 \\
\hline $\begin{array}{l}\text { Apakah bapak/saudara mau } \\
\text { melakukan penataan kebun salak } \\
\text { untuk obyek agrowisata di kebun } \\
\text { sendiri. }\end{array}$ & 28 & 72 & 0 & 0 \\
\hline
\end{tabular}

Catatan: jumlah responden 25 orang.

\subsection{Pembuatan dan Pengemasan Kuliner Berbahan Baku Buah dan Rebung Salak untuk Menudukung pengembangan Agrowisata}

Pelatihan dan pendampingan dalam pembuatan dan pengemasan kuliner berbahan baku buah dan rebung salak berlangsung lancar, diikuti dengan sangat antusias oleh seluruh peserta KWT. Pada saat pemateri memberikan penyuluhan, peserta mengikuti dengan baik, tertib dan semnagat. Pada sesi tanya jawab mereka mengajukan berbagai pertanyaan dan tanggapan. Demikian pula pada sesi praktek, peserta pelatihan mengerjakan dengan serius dan semangat, yang menunjukkan keingintahuan mereka sangat besar. Dengan keseriusan peserta dalam mengkiuti penyulahan dan pelatihan, kegiatan pengabdian ini telah berhasil mengolah kuliner dari kulit buah salak menjadi teh salak, biji salak menjadi kopi salak, daging buah salak menjadi kurma, madu dan pia salak (Gambar 2), serta rebung salak menjadi kare dan tumis salak (Gambar 3). Selain itu, kelompok wanita tani mampu memilih bahan dan bentuk kemasan yang sesuai, membuat desain label dan melakukan labeling

\section{2 | BULETIN UDAYANA MENGABDI}


dengan baik sehingga produk olahan yang dihasilkan dapat disimpan lebih lama dengan tampilan yang menarik dan mudah dikenali. Disamping itu, melalui kegiatan pendampingan, tim pengabdian bersama dengan KWT telah menghasilkan out-put berupa SOP cara membuat kuliner dalam bentuk leaflet SOP (Gambar 4).

Keberhasilan pelaksanaan penyuluhan, praktek pengolahan dan pengemasan hasil olahan salak secara kuantitatif tercermin dari jawaban peserta penyuluhan dari kuesioner yang diberikan saat kegiatan berlangsung yang semuanya menyatakan sangat puas sampai puas. Pada Tabel 3 dapat dilihat, jumlah peserta pelatihan yang menyatakan sangat puas dan puas ketika ditanyakan tentang pelaksanaan kegiatan pelatihan dan praktek pengolahan dan pengemasan adalah $68 \%$ dan $32 \%$, sehingga tidak ada $(0 \%)$ responden yang menyatakan kurang puas atau sangat tidak puas. Kepuasan yang lebih tinggi lagi diberikan oleh peserta pelatihan mengenai metode atau cara pelatih/instruktur dalam memberikan pelatihan yang dijawab sangat puas oleh $88 \%$ responden dan puas oleh $22 \%$ responden. Materi pelatihan yang disampaikan oleh pelatih mendapat skor lebih rendah dibandingkan cara atau metode pelatih memberikan pelatihan, tetapi tetap pada kisaran sangat puas $(64 \%)$ dan puas $(36 \%)$. Berdasarkan isian kuesioner pada Tabel 4 terekam juga bahwa 92\% peserta pelatihan menyatakan kuliner khas berbahan baku salak sangat berpotensi untuk dikembangkan, sisanya $8 \%$ menyatakan berpotensi. Oleh karena kuliner berbahan baku salak menurut mereka sangat berpotensi dikembangkan, maka sejumlah $96 \%$ peserta pelatihan menyatakan berminat mempraktekkan sendiri di rumah membuat kuliner berbahan baku salak untuk meningkatkan pendapatan dan sisanya $4 \%$ menyatakan berminat.

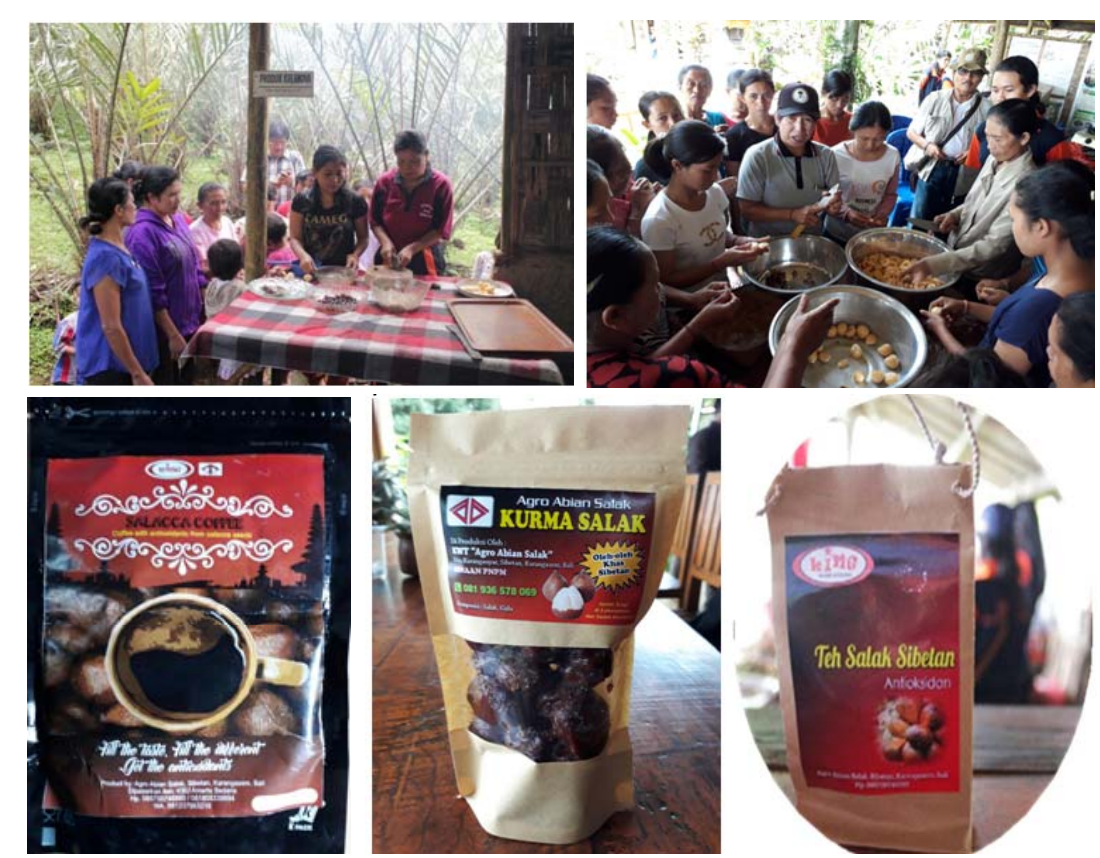

Gambar 2. Pelatihan membuat kopi salak (kiri atas) dan kurma salak (kanan atas), produk olahan kopi salak dari biji salak (kiri bawah), kurma salak dari daging buah salak (tengah bawah) dan teh salak dari kulit buah salak (kanan bawah) 

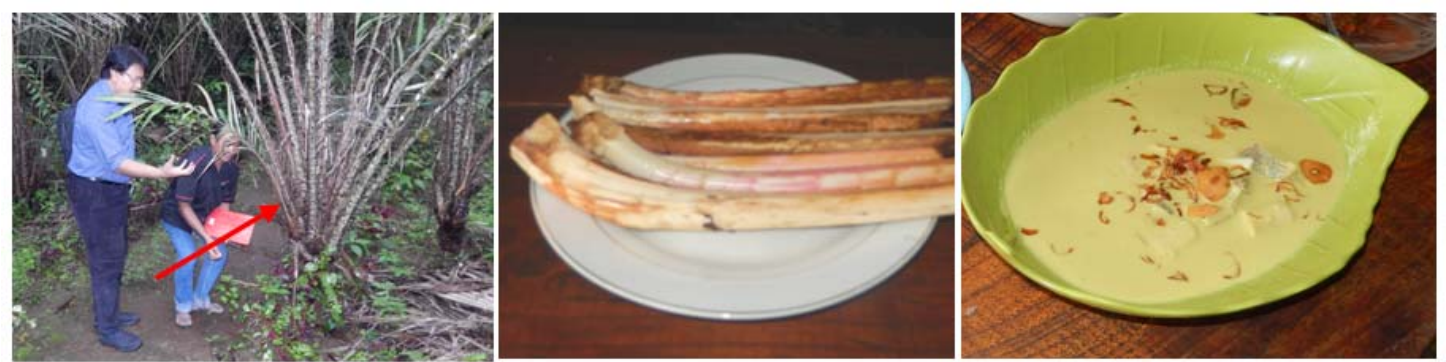

Gambar 3. Anakan salak yang dipangkas (tanda panah) diambil rebungnya (kiri), rebung (empol) salak setelah dikupas dari anakan hasil pangkasan (tengah), dan kare salak dari rebung salak (kanan).

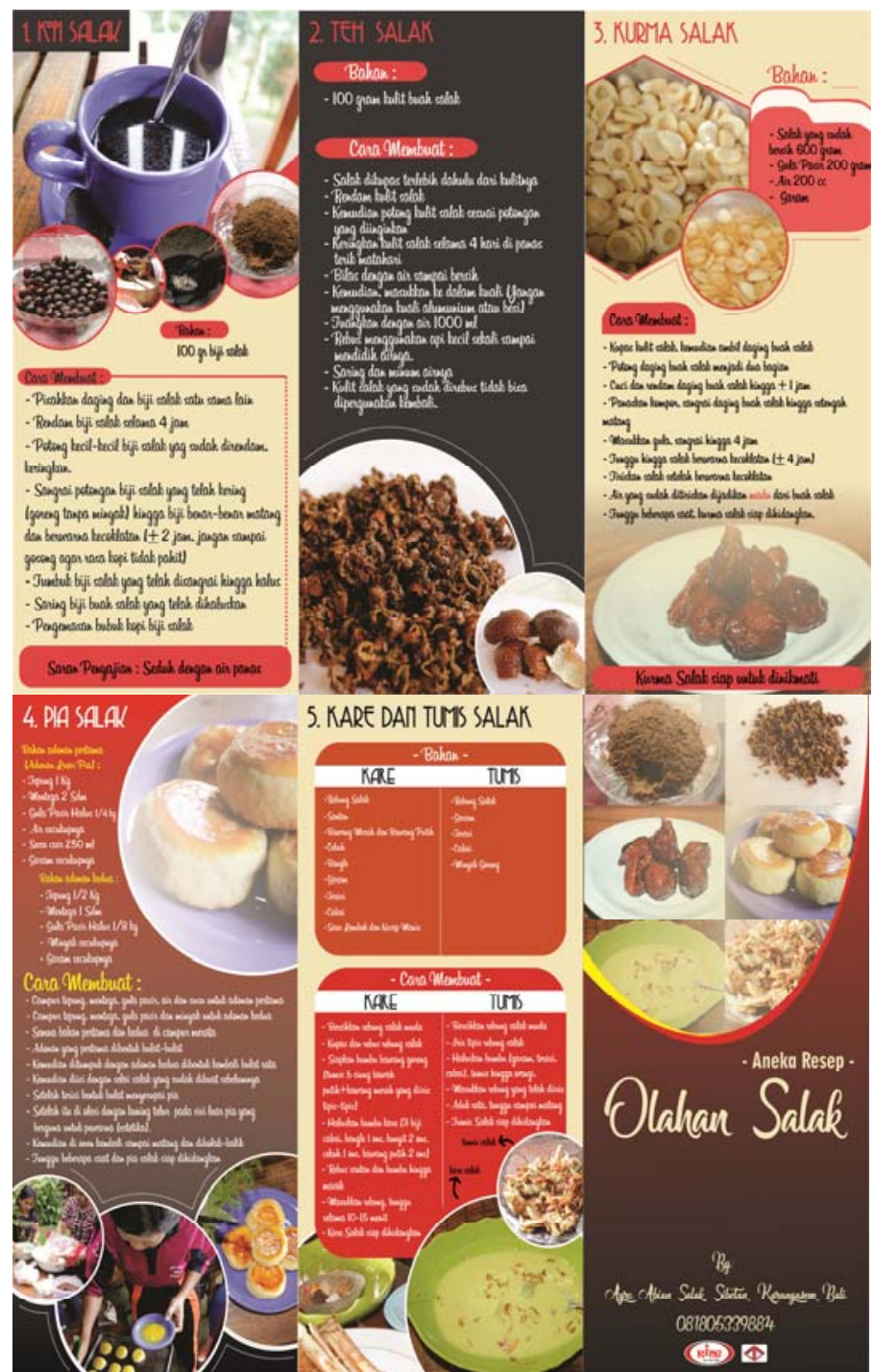

Gambar 4. Leaflet SOP cara membuat produk olahan berbahan baku buah salak dan rebung salak

\section{4 | BULETIN UDAYANA MENGABDI}


Tabel 3. Tingkat Kepuasan Peserta Pelatihan Pengolahan Buah Dan Rebung Salak Dan Teknik Labeling Kemasan

\begin{tabular}{|c|l|c|c|c|c|}
\hline \multirow{2}{*}{ No } & \multicolumn{1}{|c|}{ Pertanyaan } & \multicolumn{3}{|c|}{ Tingkat Kepuasan Peserta Penyuluhan } \\
\cline { 3 - 6 } & \multicolumn{1}{|c|}{$\begin{array}{c}\text { Sangat } \\
\text { puas }\end{array}$} & Puas & $\begin{array}{c}\text { Kurang } \\
\text { Puas }\end{array}$ & $\begin{array}{c}\text { Sangat } \\
\text { tidak Puas }\end{array}$ \\
\hline 1 & $\begin{array}{l}\text { Bagaimana pendapat ibu/saudara tentang } \\
\text { pelaksanaan kegiatan pelatihan dan praktek } \\
\text { pengolahan dan pengemasan ini. }\end{array}$ & 68 & 32 & 0 & 0 \\
\hline 2 & $\begin{array}{l}\text { Bagaimana menurut ibu/saudara mengenai } \\
\text { metode atau cara pelatih/instruktur dalam } \\
\text { memberikan pelatihannya. }\end{array}$ & 88 & 12 & 0 & 0 \\
\hline 3 & $\begin{array}{l}\text { Bagaimana menurut ibu/saudara mengenai } \\
\text { materi pelatihannya. }\end{array}$ & 64 & 36 & 0 & 0 \\
\hline 4 & $\begin{array}{l}\text { Apakah ibu/saudara merasa puas mengikuti } \\
\text { pelatihannya ini. }\end{array}$ & 44 & 56 & 0 & 0 \\
\hline
\end{tabular}

Catatan: jumlah responden 25 orang.

Tabel 4. Potensi Pengembangan Kuliner Berbahan Salak Menurut Peserta Pelatihan Dan Minat Perserta Pelatihan Mempraktekkan Sendiri Membuat Kuliner Berbahan Baku Salak

\begin{tabular}{|c|l|c|c|c|c|}
\hline No & \multicolumn{1}{|c|}{ Pertanyaan } & \multicolumn{4}{c|}{ Jawaban } \\
\hline 1. & $\begin{array}{l}\text { Apakah kuliner berbahan baku } \\
\text { salak berpotensi untuk } \\
\text { dikembangkan }\end{array}$ & $\begin{array}{c}\text { Sangat } \\
\text { berpotensi } \\
(92 \%)\end{array}$ & $\begin{array}{c}\text { Berpotensi } \\
(8 \%)\end{array}$ & $\begin{array}{c}\text { Kurang } \\
\text { berpoten } \\
(0 \%)\end{array}$ & $\begin{array}{c}\text { Sangat tidak } \\
\text { berpotensi } \\
(0 \%)\end{array}$ \\
\hline 2. & $\begin{array}{l}\text { Apakah ibu/saudara berminat } \\
\text { mempraktekkan sendiri di } \\
\text { rumah membuat kuliner } \\
\text { berbahan baku salak untuk } \\
\text { meningkatkan pendapatan. }\end{array}$ & $\begin{array}{c}\text { Sangat } \\
\text { berminat } \\
(96 \%)\end{array}$ & $\begin{array}{c}\text { Berminat } \\
(4 \%)\end{array}$ & $\begin{array}{c}\text { Kurang } \\
\text { berminat } \\
(0 \%)\end{array}$ & $\begin{array}{c}\text { Sangat tidak } \\
\text { berminat } \\
(0 \%)\end{array}$ \\
\hline
\end{tabular}

Catatan: jumlah responden 25 orang.

\section{KESIMPULAN DAN SARAN}

Berdasarkan pelaksanaan kegiatan pengabdian ini, luaran yang dicapai adalah tertatanya satu lokasi kebun salak di Desa Sibetan dilengkapi dengan berbagai paket atrakasi yang siap dikunjungi sebagai kebun agrowisata, anggota KWT mampu membuat kuliner khas dan menyusun SOP cara membuat kuliner dari kulit buah salak menjadi teh salak, biji salak menjadi kopi salak, daging buah salak menjadi kurma, madu dan pia salak, serta rebung salak menjadi kare dan tumis salak. Kelompok Wanita Tani juga mampu memilih bahan dan bentuk kemasan yang sesuai, membuat desain label dan melakukan labeling dengan baik sehingga produk olahan yang dihasilkan dapat disimpan lebih lama dengan tampilan yang menarik dan mudah dikenali.

Disarankan agar masyarakat secara mandiri melakukan penataan dan menerapkan GAP pada kebun salaknya sehingga kebunnya tertata rapi dan siap dijadikan kebun agrowisata dengan produksi yang optimal. Produk olahan buah salak yang dihasilkan agar segera diurus Surat Ijin Usaha Perdagangan (SIUP) dan HaKI-nya sehingga dapat dperdagangkan dalam skala komersial dan tidak diklaim pihak lain. 


\section{UCAPAN TERIMAKASIH}

Penulis mengucapkan terima kasih kepada Direktorat Riset dan Pengembangan Kementerian Riset, Teknologi dan Perguruan Tinggi yang mendanai pengabdian kepada masyarakat ini, juga kepada Rektor dan Ketua LPPM Universitas Udayana yang memfasilitasi pelaksanaan pengabdian. Penulis juga mengucapkan terima kasih yang sebesar-besarnya kepada Perbekel/Kepala Desa Sibetan Bapak I Nengah Kompiang suarjana, SH. atas arahan, bantuan, mediasi dan fasilitasinya, Narasumber palatihan pengolahan dan pengamasan produk olahan salak dari Fakultas Teknologi Pertanian, Universitas Udayana (Ibu Dr. Ir. Komang Ayu Nocianitri, M.Agr.Sc dan Bapak Rai Widarta, STP, M.S.) dan mahasiswa KKN Universitas Udayana Desa Sibetan Periode XV Tahun 2017.

\section{DAFTAR PUSTAKA}

Budiarti, T., Suwarto, I. Muflikhati. 2013. Pengembangan Agrowisata Berbasis Masyarakat pada Usahatani Terpadu Guna Meningkatkan Kesejahteraan Petani dan Keberlanjutan Sistem Pertanian. Jurnal Ilmu Pertanian Indonesia. 18(3): 200-207.

Budiarti, T., A.D. Listyanti. 2015. Development of Community-Based Agritourism on Integrated Farming System toward Sustainable Village. Australian Journal of Basic and Applied Sciences. 9(7):242-244.

Goodwin, H. 2008. Tourism, Local Economic Development, and Poverty Reduction. Journal of Apllied Research in Economic Development. 5(3): 55-64.

Nurisjah, S. 2001. Pengembangan kawasan wisata agro (Agrotourism). Buletin Tanaman dan Lanskap Indonesia. 4(2):20-23.

Profil Desa Sibetan Tahun 2014. Desa Sibetan, Kecamatan Bebandem, Kabupaten Karangasem. 23 hal.

Rai, I.N., G. Wijana, P. Sudana, W. Wiaatmaja, C.G.A. Semarajaya. 2016. Buah-buahan Lokal Bali: Jenis, Pemanfatan, dan Potensi Pengembangannya. Penerbit: Palawa Sari, Denpasar. ISBN: 978-602-840946-9. 286 hal.

Sudana, I.P., N.P.E. Mahadewi. 2015. Pelatihan Mengkemas Paket Agrowisata bagi Anggota Kelompok Tani di Desa Kerta, Kecamatan Payangan, Kabupaten Gianyar. Udayana Mengabdi. 14(1): 42-45.

Sumiyati, L. Sutiarso, I.W. Windia, P. Sudira. 2011. Aplikasi Analytical Hierarchy Process (AHP) untuk Penentuan Strategi Pengembangan Subak. Agritech. 31(2): 138-145.

Suyastri, N.M.Y.P. 2012. Pemberdayaan Subak Melalui “Green Tourism” Mendukung Keberlanjutan Pembangunan Pertanian di Bali. Jurnal SEPA (Sosial Ekonomi Pertanian dan Agribisnis). 8(2): 168173.

Windia, W., M. Wirartha, K. Suamba, M. Sarjana. 2011. Model Pengembangan Agrowisata Berbasis Subak di Bali. Jurnal Socio-economic of Agriculture and Agribusiness. 11(1): 81-86. 